\title{
Deprivation and escape conditioning with various intensities of shock'
}

MERLE E. MEYER, WILLIAM A. ADAMS, and VALERIE K. WORTHEN, Western Washington State College, Bellingham, Wash. 98225

Eight rats were trained to escape electric shock. In the first phase, they were given 28 trials of $1 \mathrm{~mA}$ of shock on each of 10 days; during the second 16-day phase, they received 28 trials of seven intensities randomly presented so that each intensity occurred on four trials each day; in the final 10-day phase the procedure was as Phase 2 except the $S s$ were systematically placed on a 48-h food and water deprivation schedule. The major effect of deprivation was to increase the response latencies to the electric shock.

Campbell \& Sheffield (1954) have questioned the adequacy of the drive-produced stimulus concept to account for their data when they measured the activity of rats in tilt boxes over a 7 -day period. For the first 4 days the rats were on ad lib food and water, and for the last 3 days, they were food deprived. Once each day for a brief period of time, marked changes in external stimulation were introduced. These changes produced a significant increase in general activity, with an adaptation effect setting in, over the 4 days of ad lib. When the deprivation period began, this trend was reversed producing a rise in activity with increasing hours of food deprivation. However, this increased activity occurred only during the external stimulation period. Campbell and Sheffield concluded that the effect of deprivation reduced thresholds of responses to external stimuli. It was to this hypothesis that this study addressed itself by using latency of escape, with various intensities of shock, as an index of threshold under deprivation conditions.

\section{SUBJECTS}

The Ss were eight naive 80 -day-old female Sprague-Dawley rats. They were housed in two groups of four rats each and were weighed daily before the experimental session.

\section{APPARATUS}

The experimental apparatus was a one-lever operant box housed in a sound-deadened and ventilated chamber. The stimulus shock intensities and the intertrial intervals were programmed, and the latencies measured, with standard commercial units.

\section{PROCEDURE}

During the first phase of the study, the Ss were trained to escape from a 1-mA shock. At the beginning of each trial, a shock was delivered and the Ss terminated it by a lever press which ended the trial. The response measure was the latency between the onset of shock and its termination. A variable interval of $30 \mathrm{sec}$ elapsed between trials. Twenty-eight trials were given each $S$ on each of 10 consecutive days. During this phase the Ss were on ad lib food and water.

In the second phase of 16 days, the Ss were also on ad lib food and water and were given 28 trials each day on variable intensities of shock. The intensities $(.05, .10, .20, .40, .60, .80$, and $1.00 \mathrm{~mA}$ ) were randomly presented such that each intensity was given four times during each daily session. If the Ss did not escape at the end of $60 \mathrm{sec}$, the trial was terminated. As in the first phase, the intertrial interval was a variable interval of $30 \mathrm{sec}$ and the responses measured in latencies.

During the final phase, the Ss were run for 10 daily sessions with the same procedure as in Phase 2 except that they were systematically placed on a 48 - $h$ food and water deprivation schedule alternated with $48 \mathrm{~h}$ of ad lib food and water.

\section{RESULTS}

The general results during the treatment conditions of the final phase following asymptotic performance in Phase 2 are shown in Fig. 1. A Treatment by Treatment by Subject analysis of variances of the mean latencies yielded a significant trial effect $(F=3.15$, df $=11 / 77, p>.01)$, an intensity effect $(F=171.17, \mathrm{df}=6 / 42, \mathrm{p}>.001)$, and Trial by Intensity interaction ( $F=1.42, \mathrm{df}=66 / 462, \mathrm{p}>.05)$. Because of these results, the data were blocked to test for the differences in latencies between the seven intensities and the three deprivation conditions. This Treatment by Treatment by Subject analysis indicated a significant deprivation effect $(F=8.42, \quad$ df $=2 / 14, \quad p>.005), \quad$ and intensity effect $(\mathrm{F}=167.18, \mathrm{df}=6 / 42, \mathrm{p}>.001)$, and a Deprivation by Intensity interaction $(F=1.89$, $\mathrm{df}=12 / 84, \mathrm{p}>.05)$. From Duncan's multiple range test, the overall mean latency values for the ad lib condition $(21.76 \mathrm{sec}), 24 \mathrm{~h}$ deprivation $(23.87 \mathrm{sec})$, and $48-\mathrm{h}$ deprivation $(26.46 \mathrm{sec})$ differed significantly ( $p>05$ ) among the various multiple comparisons. Comparing the mean latency values among the intensities, the $.05 \mathrm{~mA}(57.93 \mathrm{sec})$ did not differ from $.10 \mathrm{~mA}$ $(53.60 \mathrm{sec})$ but differed from the other higher intensity group values $(p>.05)$. The $.10 \mathrm{~mA}(53.60 \mathrm{sec})$ differed significantly from all higher intensities, as did the $.20 \mathrm{~mA}(31.11 \mathrm{sec})$ and the $.40 \mathrm{~mA}(14.71 \mathrm{sec})$; however, the $.60 \mathrm{~mA}(5.98 \mathrm{sec})$, the $.80 \mathrm{~mA}(2.95 \mathrm{sec})$, and the $1.00 \mathrm{~mA}(1.95 \mathrm{sec})$ did not differ significantly.

\section{DISCUSSION}

While no direct comparison can be made, the data are, in part, in keeping with the results reported by Griffiths (1962). In general, he found that food deprived animals tolerated greater intensities of shock. On the other hand, Blanchard \& Blanchard (1966) report that food and water deprivation does not affect the "flinch" or "jump" threshold under shock, and in addition the deprivation depresses the vocalization threshold. Similarly, Blanchard, Hayashi, \& Reyes (1968) found that water deprivation does not affect the reaction to electric shock.

The results of the present study would not support the hypothesis that one aspect of deprivation is to lower stimulus

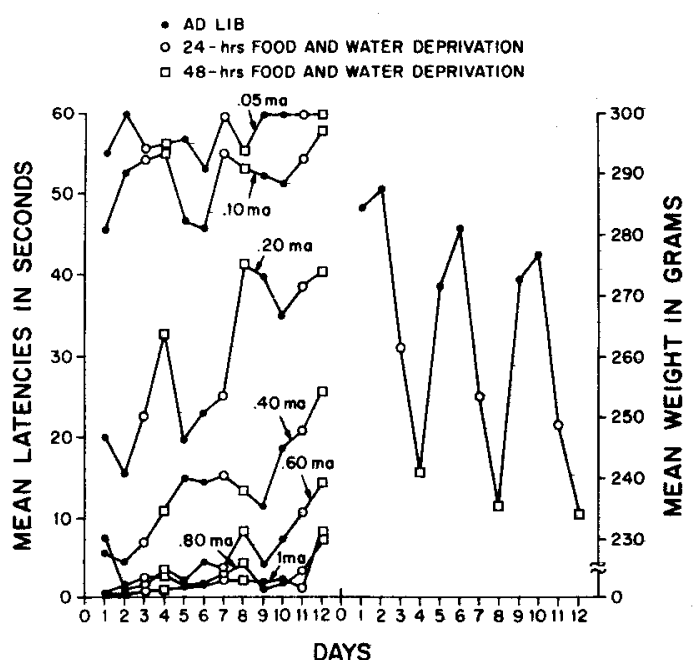

Fig. 1. Mean latencies with various intensities of electric shock under various states of deprivation over days. 
were differences in the effects of free shock on their baseline response rate; a two-tailed Wilcoxon Rank Sums Test showed that latency to the first lick in testing was longer in Group FS2 than in Group FS1 $(p<.01)$. This difference in latency was measured among Ss who made at least one lick in that session. Three Ss in Group FS2 and one in Group PC stopped responding after the first shock session and another FS2 S stopped after the free shock in testing, so that there were 11 SR Ss, 10 PC Ss, 7 FS1 Ss, and 7 FS2 Ss licking in the final session.

An analysis of variance on the habituation and extinction data for both experiments yielded highly significant evidence of learning and within-session extinction. The lack of pseudoconditioning was indicated by a significant Groups by Days interaction $(F=9.4, \mathrm{df}=3 / 34, \mathrm{p}<.001$ ).

\section{GENERAL DISCUSSION}

This attempt to facilitate a partially extinguished CER with free shock was made in order to rule out an interpretation of the failure to find any enhancement of suppression by inducing fear with free CS presentations (Quinsey \& Ayres, 1969) as merely being due to procedural differences between that experiment and Hoffman's (1965) study. While some evidence of facilitation was found in Experiment 1, the effect was not replicated in Experiment 2. These discrepant results may be due to the differential effects of free shock on the baseline lick rate of Groups FS1 and FS2. Brimer \& Kamin (1963) found that noncontingent free shock given prior to CER conditioning retarded acquisition by producing supernormal ratios at the beginning of training. The preshock had suppressed the baseline bar pressing rates of their rats and the CS, therefore, acted as a Pavlovian disinhibitor, starting Ss to respond and inflating their suppression ratios. Supernormal ratios were not found when baseline responding was allowed to recover before CER training began. The supernormal ratios of Groups FS2 and PC seem also to be a result of disinhibition by the CS.

It is strange that Groups FS1 and FS2 differed so much in resisting baseline disruption by shock since both groups of rats were obtained from the same supplier and were given the same experimental treatment. Most of the Ss used in Experiment 2 were, however, observed to be very emotional, i.e., they squealed, defecated, and urinated when handled and, very unlike other Ss used in this research, persisted in these behaviors not only through this experiment but through another study using the same apparatus and, finally, in a subsequent maze study conducted for an undergraduate students' laboratory. The maze experiment had to be terminated because most of the Ss soon started avoiding the goal boxes where they were rewarded with food and handled by the students.

If we accept the reality of the effect of shock shown by the difference between the FSI and SR groups, there still remains the problem of the nonrepresentativeness-of Group FS1 during testing. Clearly the FS1 Ss whose data were accepted from the testing session were selected for their ability to keep responding after a number of shocks. What of the Ss who stopped licking altogether? Annau \& Kamin (1961) assign zero suppression ratios to Ss who do not respond because they find that these Ss have low suppression ratios when they finally do begin to respond. If the nonresponders in the present study would have had low ratios during testing, the procedure of disregarding them would bias the results against the enhancing effect of noncontingent shock. Unfortunately, our data indicate that nonresponders do not necessarily have low suppression ratios when they begin to respond.

Baseline suppression was also a problem in another regard. To allow recovery of baseline responding for Ss receiving shocks before testing in this type of design, it is necessary to deliver the CS a fairly long time after the last shock. This delay may attenuate any enhancement produced by shock-induced fear; Baum (1967) has shown in a free operant avoidance shuttle situation with dogs that if a 17.5 min rest session is given between the last free shock and the beginning of the shuttle extinction session, the avoidance rate is markedly less enhanced than if the session follows immediately after shock.

It is concluded that if stable baseline response rates are maintained, noncontingent shocks temporarily stop extinction of the CER. The failure of Quinsey \& Ayres (1969) to arrest CER extinction with free CSs can be taken as evidence against a motivational explanation for the facilitation (or arrest of extinction) of a partially extinguished CER because of the finding that arrest can be obtained in the present paradigm. The interpretation is complicated, however, by the fact that the FSI group was selected for its ability to lick soon after shock, whereas SR Ss in the present experiment and Ss in Quinsey \& Ayres' (in press) experiment were not.

\section{REFERENCES}

ANNAU, Z., \& KAMIN, L. J. The conditioned emotional response as a function of intensity of the US. Journal of Comparative \& Physiological Psychology, 1951, 54, 428-432.

BAUM, M. Perseveration of fear measured by changes in rate of avoidance responding in dogs. Canadian Journal of Psychology, 1967, 21, 535-548.

BRIMER, C. J., \& KAMIN, L. J. Disinhibition, habituation, sensitization and the conditioned emotional response. Journal of Comparative \& Physiological Psychology, 1963, 56, 508-516.

HOFFMAN, $H$. S. The stimulus generalization of conditioned suppression. In D. I. Mostofsky (Ed.), Stimulus generalization. Stanford: Stanford University Press, 1965. Pp. 356-372.

QUINSEY, V. L., \& AYRES, J. J. B. The effect of CS-induced fear on a partially extinguished CER. Psychonomic Science, 1969, 14, 242, 244. NOTE

1. This study represents part of Vernon L. Quinsey's M.S. thesis. It was done under John J. B. Ayres' direction and was partially supported by a grant to him from the Faculty Research Council of the University of Massachusetts.

\section{(Continued from page 212)}

thresholds as measured by escape conditioned behavior. It is apparent that the major overall effect of deprivation was to increase the latencies. Thus, deprivation appears to increase the stimulus threshold, at least the threshold associated with electric shock.

\section{REFERENCES}

BLANCHARD, R. J., \& BLANCHARD, D. C. Food deprivation and reactivity to shock. Psychonomic Science, 1966, 4, 317-318.
BLANCHARD, R. J., HAYASHI, M., \& REYES, G. Water deprivation and shock threshold. Psychonomic Science, 1968, 10, 169-170.

CAMPBELL, B. A., \& SHEFFIELD, F. D. Relation of random activity to food deprivation. Journal of Comparative \& Physiological Psychology, $1953,46,320-322$.

GRIFFITHS, W. J. Effect of food and water deprivation on shock tolerance of albino rats. Psychological Reports, 1962, 11, 163-166. NOTE

1. This study was supported in part by Grant MH 13309-01 from the National Institute of Mental Health. 